\title{
Predictors of hydrocephalus as a complication of non-traumatic subarachnoid hemorrhage: a retrospective observational cohort study in 107 patients
}

Juan Manuel Vinas Rios ${ }^{1 *}$, Martin Sanchez-Aguilar ${ }^{2}$, Thomas Kretschmer ${ }^{3}$, Christian Heinen ${ }^{4}$, Fatima Azucena Medina Govea ${ }^{2}$, Sanchez-Rodriguez Jose Juan ${ }^{5}$ and Thomas Schmidt ${ }^{4}$

\begin{abstract}
Background: The predictors of shunt dependency such as amount of subarachnoid blood, acute hydrocephalus (HC), mode of aneurysm repair, clinical grade at admission and cerebro spinal fluid (CSF) drainage in excess of $1500 \mathrm{ml}$ during the 1st week after the subarachnoid hemorrhage (SAH) have been identified as predictors of shunt dependency. Therefore our main objective is to identify predictors of CSF shunt dependency following non-traumatic subarachnoid hemorrhage.

Methods: We performed a retrospective study including patients from January 1st 2012 to September 30th 2014 between 16 and 89 years old and had a non-traumatic subarachnoid hemorrhage in cranial computed tomography (CCT). We excluded patients with the following characteristics: Patients who died 3 days after admittance, lesions in brainstem, previous surgical treatment in another clinic, traumatic brain injury, pregnancy and disability prior to SAH. We performed a descriptive and comparative analysis as well as a logistic regression with the variables that showed a significant difference $(p<0.05)$. Hence we identified the variables concerning $\mathrm{HC}$ after non traumatic SAH and its correlation.

Results: One hundred and seven clinical files of patients with non-traumatic SAH were analyzed. Twenty one (48\%) later underwent shunt treatment. Shunt patients had significantly clinical and corroborated with doppler ultrasonography vasospasmus $(p=0.015), \mathrm{OR}=5.2$. The amount of subarachnoidal blood according to modified Fisher grade was $(p=0.008) \mathrm{OR}=10.9$. Endovascularly treated patients were less often shunted as compared with those undergoing surgical aneurysm repair $(p=0.004)$.

Conclusion: Vasospasmus and a large amount of ventricular blood seem to be a predictor concerning hydrocephalus after non-traumatic SAH. Hence according to our results the presence of these two variables could alert the treating physician in the decision whether an early shunt implantation $<7$ days after SAH should be necessary.
\end{abstract}

Keywords: Hydrocephalus, Shunt dependency, Subarachnoid hemorraghe, Vasospasmus, Intraventricular hemorraghe

\footnotetext{
* Correspondence: vinasrios@outlook.com

${ }^{1}$ Sana Spine center, Klinikum Offenbach, Bruchfeld Str. 74, 60528 Offenbach,

Germany

Full list of author information is available at the end of the article
}

(c) The Author(s). 2018 Open Access This article is distributed under the terms of the Creative Commons Attribution 4.0 International License (http://creativecommons.org/licenses/by/4.0/), which permits unrestricted use, distribution, and reproduction in any medium, provided you give appropriate credit to the original author(s) and the source, provide a link to the Creative Commons license, and indicate if changes were made. The Creative Commons Public Domain Dedication waiver (http://creativecommons.org/publicdomain/zero/1.0/) applies to the data made available in this article, unless otherwise stated. 


\section{Background}

Spontaneous subarachnoid hemorrhage (SAH) is one of the most common disorders within the vast neurological field involving morbidity-mortality. The mean age of presentation is at the age of 55 years, affecting younger people that the rest of the cerebral insults such as cerebral ischemia [1].

Hydrocephalus ( $\mathrm{HC}$ ) is a frequent complication of $\mathrm{SAH}$. While acute $\mathrm{HC}$ is present in $15-87 \%$ [2-6], chronic $\mathrm{HC}$ has been reported in $9-64 \%$ of SAH [7-13].

Acute $\mathrm{HC}$ requires urgently cerebrospinal fluid (CSF) drainage in order to reduce the intracranial pressure (ICP) and to avoid cerebral herniation. Early CSF drainage has been proven to be beneficial in reducing secondary effects from SAH. Shunt surgery carries risks of complications such as cerebral bleeds, subdural hematoma and infection [14-18]. The predictors of shunt dependency such as amount of subarachnoid blood, acute $\mathrm{HC}$, mode of aneurysm repair, clinical grade at admission and CSF drainage in excess of $1500 \mathrm{ml}$ during the 1st week after the ictus have been identified as predictors of shunt dependency. Nevertheless there are discrepancies in these predictor factors about their influence in patients being shunted $[3,7,9,12,13,19,20]$. Taking in count these discrepancies our main objective was to confirm and/or to reveal, until now, not taken in count predictor factors in shunt dependency following spontaneous subarachnoid hemorrhage.

\section{Methods}

We developed a retrospective study. We evaluated clinical profiles of 107 patients included from January 1st 2012 to September 30th 2014. We compared shunted and non-shunted patients with regard age, gender, clinical grade at admission (Hunt and Hess grade), aneurysm location, amount of subarachnoid blood (modified Fisher grade), amount of interventricular blood (LeRoux), and ventricular size (Evans Index, third ventricle index and ventricular score) on preoperative cranial computer tomography (CCT). We further compared the treatment modality, surgical opening of the lamina terminalis, decompressive craniectomy, use of ventricular/Lumbar CSF drains, and volume of CSF drained during week 1 and weeks $1-3$ in the two patients groups (shunted vs. non-shunted patients).

Inclusion Criteria:

- Patients between 16 and 89 years old

- Non-traumatic subarachnoid hemorrhage in cranial computed tomography (CCT)

The evaluated patients were included from the registries from the University Clinic Evangelisches
Krankenhaus, Oldenburg, Germany. Twenty patients that did not fulfill the inclusion criteria were excluded.

The present study was carried out in a high-volume over-regional neurosurgical center managing approximately 100 non-traumatic SAH patients yearly from a defined catchment area where the national government covers all medical expenses. To limit other biases with regard to defining $\mathrm{HC}$ after spontaneous $\mathrm{SAH}$, we simply defined shunt dependency as having received a shunt.

Exclusion criteria:

- Patients who died 3 days after admittance.

- Lesions in the intraparenchymatous brainstem as an isolated finding.

- Previous surgical treatment in another clinic.

- Pregnancy.

- Prior disability to SAH.

- Traumatic brain injury

\section{Management and Intervention}

The patients were admitted to the emergency room and handled according to the guidelines of Advanced Trauma Life Support (ATLS). Once the patients were stabilized CCT scan were taken.

The routine treatment included a crystalloid solution, gastric protector, analgesic and sedative in case of agitation. For intubation purposes we used propofol plus rocuronium.

At the admittance we performed a native CCT and CT-angiography, if negative a four vessels 3D Digital Substraction Angiographie (DSA) was obtained; if this still remains negative an MRI plus MRI-angiography was done. After negative results for an aneurysm bleeding in MRI plus MRA-angiography, we admitted the patient in the ICU performing Intracranial Doppler Ultrasonography. If Vasospasm was diagnosticated, the Intracranial Doppler Ultrasonography was performed every $24 \mathrm{~h}$. If the DSA and the MRI plus MRI- angiography was negative, the $\mathrm{SAH}$ was classified as spontaneous prepontine $\mathrm{SAH}$ and was treated conservatively.

We defined patients receiving a shunt as shunt depending patients. The decision for shunting was based on our institutional treatment algorithm.

The radiological evaluation of the amount of subarachnoid and ventricular blood, as well as ventricular size, was performed retrospectively. The amount of SAH was evaluated using the modified Fisher grade. We further differentiated between supra- and infratentorial bleeds. For linear measures of ventricular size, we determinate the Evans index, Third ventricle index and ventricular score. The LeRoux scoring system was used for grading the amount of interventricular blood.

All the patients were managed with the goal of obtaining a mean ICP threshold of less than $20 \mathrm{mmHg}$. 


\section{Statistical analysis}

We utilized the program JMP-7. We completed an analysis of descriptive statistics, obtaining the measures of central tendency and dispersion of all the variables. For the comparative analysis we used the Student's t-test for continuous variables with normal distribution and the Wilcoxon/Kruskal-Wallis test for continuous variables without normal distribution. For categorical variables the Chi-squared test was applied and for tables with boxes less than 5 , the Fisher's exact test was utilized. Statistical significance was considered with a value of $p<0.05$. We calculated the Odds Ratio (OR) with of Confidence Intervals (CI) of $95 \%$. We made an analysis of logistic regression with the variables that showed a significant difference $(p<0.05)$ in the bivariate analysis. In the final model, they were expressed with OR (CI 95\%), as well as with multiple coefficient correlation R2.

\section{Results}

In our study almost the half of the patients (41\%) received an external ventricle or lumbar CSF drains (EVD/ LD). From these 44/107 patients (41\%), 21 (48\%) later underwent a permanent CSF drain. They were shunted with a median of 15.3 days (12.5-17.7) after bleed. The elected treatment of the patients with a proven aneurysm was: 40 endovascular, 39 with surgical clipping and 28 were treated conservative as prepontine SAH. Two patients (1.8\%) underwent shunt treatment without previously EVD/LD placement.

The aneurysm location was not significantly different between the shunt and non-shunt groups.

The amount of subarachnoid blood according to modified Fisher grade as presented in Table 1 was $(p=$ 0.008). While the non-shunted group had a larger fraction of patients with minimal SAH, shunted patients had a higher fraction of patients with large SAH. Moreover, shunted patients had significantly more intraventricular blood (LeRoux 4 or more, Table 1).

The linear measures of ventricular size also differed significantly between groups with shunt patients having significantly larger ventricles in terms of ventricular score at admission compared to the non-shunted patients $(p=0.003)$ (see Fig. 1).

Endovascular treated patients were less often shunted as compared with those undergoing surgical aneurysm repair $(20 \%$ vs $26 \%, p=0.004)$. Moreover EVD/LD and decompressive craniectomy were significant between the treatment groups (60\% vs $36 \%, p=0.03$ and 0 vs $18 \%, p$ $=0.001$ respectively). The surgical opening of the lamina terminalis was not significant between the groups. From the patients with prepontine $\mathrm{SAH}$, treated conservatively 3 (14\%) received a shunt (not shown).
Shunted patients had not significantly higher volumes of CSF drainage during week 1 and week 1-3 as compared to those that were not shunted.

The endovascular treated patients had a higher ventricular score at the admittance $71.5(58-94.7)$ vs 70.2 (66.8-73.6), $p<0.001$. There was a larger amount of intraventricular blood in patients who were treated endovascular. The mode of aneurysm repair was closely linked to aneurysm location $(p<0.001)$; thus, while $21(54 \%)$ patients that bled from middle cerebral artery aneurysms underwent surgical repair, 11 of the 15 patients with vertebrobasilar artery aneurysm bleeds were treated endovascular (Table 2).

The volume of CSF drained during both week 1 and weeks 1-3, age, gender, preoperative Hunt and Hess grade and amount of subarachnoid blood did not differ significantly between patients undergoing surgical versus endovascular aneurysm repair.

In the univariable analysis (Table 3), vasospasm was a strong predictor with an odds ratio (OR) of 5.2 for shunt dependency when compared with patients that did not develop this condition. Larger amounts of intraventricular blood increased the likelihood of shunt dependency, with ORs of 10.9 for intraventricular blood with LeRoux score $\geq 4$.

\section{Discussion}

The main findings of this study were that shunt dependency after spontaneous SAH could be predicted by larger amounts of subarachnoid and ventricular blood or large ventricular size being high on admission $\mathrm{CT}$ scans, clinical and doppler ultrasonographic vasospasm and the colocation of a drainage system (EVD/LD). Meaning that patients with large amounts of intraventricular blood in the CT on admission (LeRoux score $\geq 4$ ) with EVD/LD colocation because of acute hydrocephalus and consequent vasospasm because of the large amount of blood with intracerebral vessels irritation/inflammation and adhesion in the ventricular and subarachnoid space causing CSF circulation disturbances.

\section{Patient material}

Our patient material consisted of 107 retrospective spontaneous SAH patients including those with non-aneurysm finding. The patients received their shunt either after unsuccessful weaning of a temporary CSF drain during the primary stay or, less common during re-hospitalization at our department due to secondary clinical deterioration combined with increasing ventricular size.

Median time from ictus to shunting was 15 days. The mode of weaning of temporary CSF drainage does not seem to influence the frequency of shunt dependency 10 , and our treatment protocol should hence not be 
Table 1 Demographic, clinical, and radiological variables at admission and early management of the studied patients

\begin{tabular}{|c|c|c|c|}
\hline & Shunt $(n=21)$ & Non-Shunt $(n=86)$ & $p$-Value \\
\hline Gender (M/F) & $6 / 15$ & $42 / 44$ & 0.53 \\
\hline Age (years) (median, range) & 57 (29-78) & $56(21-83)$ & 0.77 \\
\hline \multicolumn{4}{|l|}{ Clinical grade at admission } \\
\hline$H-H^{a} 1-3$ & $15(71.4 \%)$ & 65 (75.5\%) & \multirow[t]{2}{*}{0.72} \\
\hline $\mathrm{H}-\mathrm{H}^{\mathrm{a}} 4-5$ & $6(28.6 \%)$ & $21(24.5 \%)$ & \\
\hline \multicolumn{4}{|l|}{ Radiology at admission } \\
\hline Modified Fisher 1 + 2 (minimal SAH) & $3(14.2 \%)$ & $38(44.2 \%)$ & \\
\hline Modified Fisher $3+4$ (large SAH) & $18(85.8 \%)$ & $48(55.8 \%)$ & \multirow[t]{2}{*}{0.008} \\
\hline Bleeding Supratentorial & $5(24 \%)$ & $18(21 \%)$ & \\
\hline Bleeding Infratentorial & $1(5 \%)$ & 0 & 0.09 \\
\hline Evans index (median, range) & $0.29(0.23-0.33)$ & $0.27(0.21-0.36)$ & \multirow[t]{2}{*}{0.52} \\
\hline Third ventricle in $\mathrm{mm}$ & $8(4.7-13.7)$ & $6.9(3-14.3)$ & \\
\hline Ventricular Score & $79.3(60-92.6)$ & $70(51-103.7)$ & 0.003 \\
\hline \multicolumn{4}{|l|}{ Aneurysmal Source of bleeding } \\
\hline Middle cerebral artery & $7(33 \%)$ & $20(23 \%)$ & \\
\hline Internal carotid artery & $3(14 \%)$ & $8(9 \%)$ & \\
\hline Anterior cerebral artery & $5(24 \%)$ & $21(24 \%)$ & \\
\hline Posterior circulation & $4(19 \%)$ & $11(13 \%)$ & \\
\hline Non-aneurysmal & $2(9 \%)$ & $26(30 \%)$ & 0.08 \\
\hline \multicolumn{4}{|l|}{ Surgical Intervention } \\
\hline $\mathrm{EVD} / L D^{\mathrm{b}}$ & $16(76 \%)$ & $28(32 \%)$ & $<0.001$ \\
\hline Lamina Terminalis Opening & $5(24 \%)$ & $17(20 \%)$ & 0.09 \\
\hline Decompressive craniectomy & $1(5 \%)$ & $6(7 \%)$ & 0.07 \\
\hline \multicolumn{4}{|l|}{ CSF Drainage } \\
\hline Drainage week 1 (ml) (median, range) & $1523 \pm 158$ & $1258 \pm 122$ & 0.63 \\
\hline Drainage week 1-3 (ml) (median, range) & $3364 \pm 308$ & $2683 \pm 233$ & 0.76 \\
\hline Clinical vasospasm & $15(71 \%)$ & $36(42 \%)$ & 0.015 \\
\hline
\end{tabular}

Significant differences between groups were determined by chi-square test or Fisher exact test for dichotomized or categorical data as appropriate Continuous data were determined using independent sample T-student test or Mann-Whitney U-test

${ }^{a}$ HH Hunt and Hess grade

${ }^{b}$ EVD/LD Extraventricular drainage or lumbar drainage performed

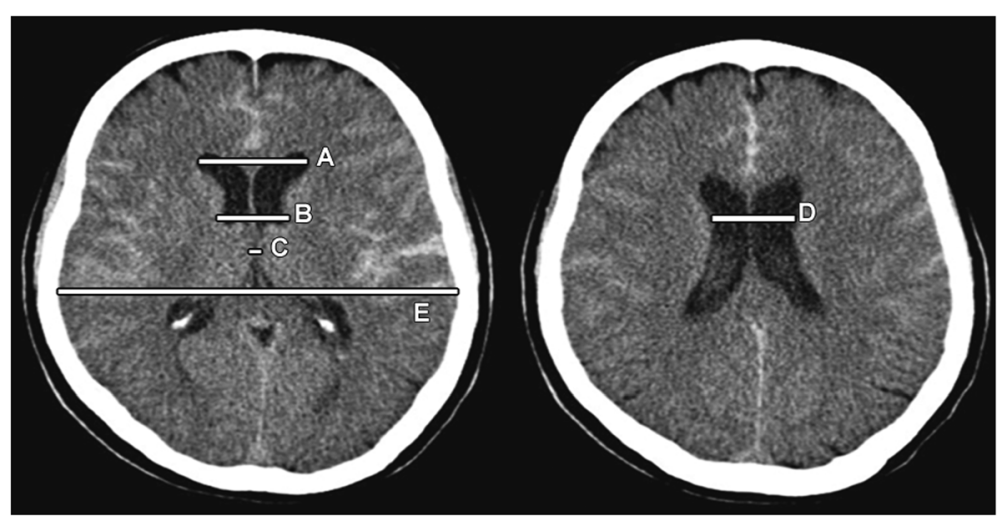

Fig. 1 Example of ventricle size estimation 
Table 2 Endovascular treatment (EVT) versus surgical treatment (clipping) in the studied patients

\begin{tabular}{|c|c|c|c|}
\hline & $\mathrm{EVT}(n=40)$ & Surgical $(n=39)$ & $p$-Value \\
\hline Gender (M/F) & $16 / 24$ & $13 / 26$ & 0.75 \\
\hline Age (years) & $53(21-80)$ & $55(23-77)$ & 0.87 \\
\hline \multicolumn{4}{|l|}{ Clinical grade at admission $\mathrm{H}-\mathrm{H}$} \\
\hline$H-H^{a} 1-3$ & $27(67.5 \%)$ & $25(64 \%)$ & \multirow[t]{2}{*}{0.08} \\
\hline $\mathrm{H}-\mathrm{H}^{\mathrm{a}} 4-5$ & $13(32.5 \%)$ & $14(36 \%)$ & \\
\hline \multicolumn{4}{|l|}{ Radiology At Admission } \\
\hline Modified Fisher 1 + 2 (minimal SAH) & $12(30 \%)$ & $8(20.5 \%)$ & \multirow[t]{3}{*}{0.08} \\
\hline Modified Fisher 3 + 4 (large SAH) & $28(70 \%)$ & $31(79.5 \%)$ & \\
\hline Bleeding Supratentorial & $6(15 \%)$ & $17(43 \%)$ & \\
\hline Bleeding Infratentorial & 0 & $1(2 \%)$ & 0.006 \\
\hline Evans index & $0.28(0.22-0.34)$ & $0.27(0.21-0.33)$ & 0.45 \\
\hline Ventricular Score & $71.5(58-94.7)$ & $70.2(66.8-73.6)$ & 0.001 \\
\hline Le Roux 0-3 & 0 & $7(18 \%)$ & 0.001 \\
\hline Le Roux $\geq 4$ & $40(100 \%)$ & $32(82 \%)$ & \\
\hline \multicolumn{4}{|l|}{ Aneurysmal source of bleeding } \\
\hline Middle cerebral artery & $6(40 \%)$ & $21(54 \%)$ & \\
\hline Internal carotid artery & $8(20 \%)$ & $3(8 \%)$ & \\
\hline Anterior cerebral artery & $15(37 \%)$ & $11(28 \%)$ & \\
\hline Posterior circulation & $11(27 \%)$ & $4(11 \%)$ & 0.001 \\
\hline \multicolumn{4}{|l|}{ Surgical intervention } \\
\hline Shunt & $8(20 \%)$ & $10(26 \%)$ & 0.004 \\
\hline EVD/LD & $24(60 \%)$ & $14(36 \%)$ & \multirow[t]{2}{*}{0.03} \\
\hline Lamina Terminalis Opening & N/A & $22(56 \%)$ & \\
\hline Decompressive craniotomy & 0 & $7(18 \%)$ & 0.001 \\
\hline \multicolumn{4}{|l|}{ CSF Drainage } \\
\hline Drainage week 1 (ml) (median, range) & $1427 \pm 456$ & $1495 \pm 772$ & 0.72 \\
\hline Drainage week 1-3 (ml) (median, range) & $2635 \pm 1020$ & $3107 \pm 1240$ & 0.67 \\
\hline Clinical Vasospasmus & $27(67 \%)$ & $16(41 \%)$ & 0.023 \\
\hline
\end{tabular}

Significant differences between groups are determined by Pearson chi-square test. Continuous data were determined using the independent sample $\mathrm{t}$ test ${ }^{a} \mathrm{HH}$ Hunt and Hess grade

${ }^{b}$ EVD/LD Extraventricular drainage or lumbar drainage performed

crucial to the observed results. A weakness of the present study was the limited number of patients investigated and the retrospective data collection.

\section{Treatment algorithm for SAH patients}

The patients included followed this department's routine for management of SAH patients. In short, our policy includes immediate identification of the origin of

Table 3 Best logistic regression model for shunt dependency

\begin{tabular}{lllll}
\hline Parameter & OR & Lower 95\% & Upper 95\% & $p$ value \\
\hline Vasospasmus & 5.7 & 4.7 & 6.7 & 0.016 \\
$\begin{array}{l}\text { Intraventricular Hemorrhage } \\
\text { (LeRoux } \geq 4 \text { ) }\end{array}$ & 10.9 & 8.0 & 12.8 & $<0.001$ \\
\hline
\end{tabular}

hemorrhage, early aneurysm repair, and rigorous prevention of secondary brain damage.

Rigorous CSF drainage is used during the early period. In patients with evidence of shunt dependency, we advocate early shunt implantation.

\section{Assessment and treatment of chronic hydrocephalus after SAH}

Assessment of chronic $\mathrm{HC}$ after spontaneous SAH is a challenge. Actually, since there is no single test to determine the presence or absence of shunt-dependent $\mathrm{HC}$, it becomes difficult to determine the frequency of chronic $\mathrm{HC}$ after spontaneous SAH and therefore a shunt system implantation. This could partly be the reason why the literature reports frequencies of chronic $\mathrm{HC}$ ranging 
from 9 to $64 \%$ after spontaneous $\mathrm{SAH}[3,8,9,11,12]$. In this study, $20 \%$ of the patients were shunted, a number according within mentioned reports.

\section{Shunt dependency versus clinical, radiological and aneurysmal variables}

Many studies have found that acute $\mathrm{HC}$ predicts shunt dependency/chronic $\mathrm{HC}[3,8,19,21,22]$. It has been proven that clinical grade at admission, a larger amount of subarachnoid blood and large ventricular size on preoperative cerebral CT, and particularly CSF drainage in excess of $1500 \mathrm{ml}$ during the 1st week after the ictus were significant predictors of shunt dependency [23].

In our study the shunted patients had larger cerebral ventricles on $\mathrm{CT}$ scans at admission than the non-shunted patients, i.e., the ventricular score was a significant predictor of shunt dependency.

As observed by others and in the present study, the amount and distribution of subarachnoid blood is, per se, a significant predictor of later shunt dependency after $\mathrm{SAH}$ [5]. This blood then interacts with tissue and leads to disturbed CSF circulation [6]. On the other hand, hydrocephalus has been discovered as a complication of spontaneous subarachnoid hemorrhaging, manifesting in ventricular hemorrhaging, vasospasm, and aneurysms of the posterior segment as well as damage due to intraoperative manipulation $[24,25]$. This last asseveration correlate with our finding that patients treated with surgical clipping underwent more shunt system colocation in contrast with the patients treated with coiling. This could be explained because of the intraoperative manipulation with consequent induction of vasospasm; thus disturbed CSF circulation could be due to fibrosis of the subarachnoid space.

In our univariable logistic regression analysis, we found clinical and doppler ultrasonographic vasospasmus to be a predictor of shunt dependency. Intraventricular hemorrhage hence increased the likelihood of developing shunt dependency. This concurs with findings by others $[6,9,22,26]$.

Most vertebrobasilar aneurysms were treated endovascular in our study. This could explain the finding that aneurysm location was not a predictor of shunt dependency in the multivariable analysis.

\section{Shunt dependency versus treatment variables}

In our multivariable analysis we found that clinical and doppler ultrasonographic vasospasm together with intraventricular blood at admittance were the strongest predictor of later shunt dependency; vasospasm hence increased the likelihood to become shunted almost 5 times and intraventricular blood 10.9 times.

Recent experimental studies have demonstrated abnormally increased CSF production following spontaneous
SAH, which might be an important pathophysiological mechanism behind acute HC after spontaneous SAH [26].

The effect of the mode of aneurysm repair on shunt dependency has been discussed in the literature [15, 17, 27]. It has been concluded that there is less risk for developing shunt-dependent HC after surgical clipping as compared to endovascular aneurysm repair [27].

Although prepontine SAH is considered a bleeding with a better prognostic in comparison with aneurysm bleeding [28], it has been described as producing hydrocephalus in a mild number of patients suffering this condition as seen in our study. A predictor factor in developing chronic hydrocephalus after prepontine $\mathrm{SAH}$ is a heavy clot burden (Fisher grade 3) [29].

In the multivariable logistic regression analysis, however, mode of aneurysm repair was not a significant predictor. The effect of surgical opening of the lamina terminalis on the development of chronic $\mathrm{HC}$ has been debated. Whereas the guidelines for treatment of spontaneous SAH patients do not recommend opening of the lamina terminalis $[2,30]$, however it has been found lamina terminalis fenestration to be effective in preventing chronic HC. Our findings do not support this notion.

Many of the previously published predictive factors for shunt dependency are interwoven. Presently, the multivariable logistic regression analysis is helpful in sorting out which predictors are relevant per se. The data of this study suggest that patients with a large amount of intraventricular blood at admission and patients developing clinical and doppler ultrasonographic vasospasm should be considered for shunt placement as soon as possible.

As shortcoming in our study, based in our result, the following asseverations could be assessed:

- Patients suffering vasospasmus in the 1st week after Hemorrhage have a higher risk to develop hydrocephalus.

- Large amounts of intraventricular blood after SAH is the most significant factor in developing posthemorrhagic hydrocephalus.

- The amount of drained CSF and localization of the aneurysm, after SAH does not play a role in developing hydrocephalus.

- At the beginning of our study seemed to be clipping aneurysm repair a risk factor for developing hydrocephalus. After the logistic regression analysis it was discharged as a variable for outcome regarding post-hemorrhagic hydrocephalus.

\section{Conclusions}

In this retrospective study, vasospasmus and a large amount of ventricular blood seem to be a predictor concerning hydrocephalus after non-traumatic SAH. Hence the presence of these two variables could alert the 
treating physician in the decision whether an early shunt implantation $<7$ days after SAH should be necessary. For a more accurate representation of this phenomenon, prospective studies with a larger amount of patients and a longer follow up in shunted patients with post-hemorrhagic hydrocephalus should be performed.

\section{Acknowledgments}

The publication costs for this article were covered in full by a grant from the Colorado Physician Insurance Company (www.copic.com) to Philip F. Stahel, MD. COPIC had no influence on authorship or scientific content of this article.

\section{Availability of data and materials}

The datasets generated and/or analysed during the current study are available by the Author Vinas-Rios, Juan Manuel.

\section{Authors' contributions}

VRJ: carried out main manuscript writing, literature research and owner of the idea in this research. SAM: carried out the statistical analysis. KT: contributed with ideas and literature searching. HC: contributed with ideas and literature searching. MGF: contributed with Figures and tables as well as manuscript writing. SRJJ: carried out part of the statistical analysis. ST: Senior reviewer. All authors read and approved the final manuscript.

\section{Ethics approval and consent to participate}

All procedures performed in studies involving human participants were in accordance with the ethical standards of the institutional and/or national research committee and with the 1964 Helsinki declaration and its later amendments or comparable ethical standards. Informed consent: Informed consent was obtained from all individual participants included in the study.

\section{Competing interests}

All authors certify that they have no affiliations with or involvement in any organization or entity with any financial interest (such as honoraria; educational grants; participation in speakers' bureaus; membership, employment, consultancies, stock ownership, or other equity interest; and expert testimony or patent-licensing arrangements), or non-financial interest (such as personal or professional relationships, affiliations, knowledge or beliefs) in the subject matter or materials discussed in this manuscript.

\section{Publisher's Note}

Springer Nature remains neutral with regard to jurisdictional claims in published maps and institutional affiliations.

\section{Author details \\ ${ }^{1}$ Sana Spine center, Klinikum Offenbach, Bruchfeld Str. 74, 60528 Offenbach, Germany. ${ }^{2}$ Clinic epidemiology, Universidad Autonoma de San Luis Potosi, San Luis Potosí, Mexico. ${ }^{3}$ Department of neurosurgery, Klinikum Klagenfurt, Klagefurt, Austria. ${ }^{4}$ Department of neurosurgery, University clinic Evangelical Hospital Oldenburg, Oldenburg, Germany. ${ }^{5}$ Department of neurosurgery Klinikum Braunschweig, Braunschweig, Germany.}

Received: 27 January 2018 Accepted: 8 May 2018

Published online: 22 May 2018

\section{References}

1. van Lieshout JH, Fischer I, Kamp MA, et al. Subarachnoid hemorrhage in Germany between 2010 and 2013: estimated incidence rates based on a Nationwide Hospital discharge registry. World Neurosurg. 2017;104:516-21.

2. Connolly ES Jr, Rabinstell AA, Carhuapoma JR, et al. Guidelines for the management of aneurysmal subarachnoid hemorrhage: a guideline for healthcare professionals from the American Heart Association/american Stroke Association. Stroke. 2012;43:1711-37.

3. Dehdashti AR, Rilliet B, Rufenacht DA, de Tribolet N. Shunt- dependent hydrocephalus after rupture of intracranial aneurysms: a prospective study of the influence of treatment modality. J Neurosurg. 2004;101:402-7.
4. Auer LM, Mokry M. Disturbed cerebrospinal fluid circulation after subarachnoid hemorrhage and acute aneurysm surgery. Neurosurgew. 1990;26:804-8. discussion 808-809

5. Tapaninaho A, Hernesniemi J, Vapalahti M, et al. Shunt-dependent hydrocephalus after subarachnoid haemorrhage and aneurysm surgery: timing of surgery is not a risk factor. Acta Neurochir. 1993;123:118-24.

6. Yoshioka H, Inagawa T, Tokuda Y, et al. Chronic hydrocephalus in elderly patients following subarachnoid hemorrhage. Surg Neurol. 2000;53:119-24. discussion 124-115

7. de Oliveira JG, Beck J, Setzer M, et al. Risk of shunt-dependent hydrocephalus afier occlusion of ruptured intracranial aneurysms by surgical clipping or endovascular coiling: a single-institution series and metaanalysis. Neurosurgery. 2007;61:924-33. discussion 933-924

8. Demirgil BT, Tugcu B, Postalci L, et al. Factors leading to hydrocephalus after aneurysmal subarachnoid hemorrhage. Minim Invasive Neurosurg. 2003;46:344-8.

9. Dorai Z, Hynan LS, Kopitnik TA, et al. Factors related to hydrocephalus after aneurysmal subarachnoid hemorrhage. Neurosurgery. 2003;52:763-9. discussion 769-771

10. Klopfenstein JD, Kim LJ, Feiz-Erfan I, et al. Comparison of rapid and gradual weaning from external ventricular drainage in patients with aneurysmal subarachnoid hemorrhage: a prospective randomized trial. J Neurosurg. 2004;100:225-9.

11. Kolluri VR, Sengupta RP. Symptomatic hydrocephalus following aneurysmal subarachnoid hemorrhage. Surg Neurol. 1984;21:402-4.

12. Woernle CM, Winkler KM, Burkhardt JK, et al. Hydrocephalus in 389 patients with aneurysm-associated subarachnoid hemorrhage. J Clin Neurosci Off J Neurosurg Soc Australas. 2013;20:824-6.

13. Yang TC, Chang CH, Liu YT, et al. Predictors of shunt-dependent chronic hydrocephalus after aneurysmal subarachnoid haemorrhage. Eur Neurol. 2013;69:296-303.

14. Eide PK, Sorteberg W. Diagnostic intracranial pressure monitoring and surgical management in idiopathic normal pressure hydrocephalus: a 6-year review of214 patients. Neurosurgery. 2010;66:80-91.

15. Korinek AM, Fulla-Oller L, Boch AL, et al. Morbidity of ventricular cerebrospinal fluid shunt surgery in adults: an 8-year study. Neurosurgery. 2011;68:985-94. discussion 994-985

16. Misaki K, Uchiyama N, Hayashi Y, et al. Intracerebralhemorrhage secondary to ventriculoperitoneal shunt insertion-four case reports. Neurol Med Chir. 2010;50:76-9.

17. Reddy GK, Bollam P, Shi R, et al. Management of adult hydrocephalus with ventriculoperitoneal shunts: long-term single-institution experience. Neurosurgery. 2011;69:774-80. discussion 780-771

18. Wong JM, Ziewacz JE, Ho AL, et al. Patterns in neurosurgical adverse events: cerebrospinal fluid shunt surgery. Neurosurg Focus. 2012;33:E13.

19. Rincon F, Gordon E, Starke RM, et al. Predictors of long-term shuntdependent hydrocephalus after aneurysmal subarachnoid hemorrhage. Clin Artic J Neurosurg. 2010;113:774-80.

20. Sugawara T, Maehara T, Nariai T, et al. Independent predictors of shuntdependent normal pressure hydrocephalus after aneurysmal subarachnoid hemorrhage. J Neurosurg Sci. 2016;60(2):154-8.

21. Kwon JH, Sung SK, Song YJ, et al. Predisposing factors related to shuntdependent chronic hydrocephalus after aneurysmal subarachnoid hemorrhage. J Korean Neurosurg Soc. 2008;43:177-81.

22. Lai L, Morgan MK. Predictors of in-hospital shunt-dependenthydrocephalus following rupture of cerebral aneurysms. J Clin Neurosci. 2013;20:1134-8.

23. Erixon $\mathrm{HO}$, Sorteberg $\mathrm{A}$, Sorteberg $\mathrm{W}$, et al. Predictors of shunt dependency after aneurysmal subarachnoid hemorrhage: results of a single-center clinical trial. Acta Neurochir. 2014;156:2059-69.

24. Jovanovi V, Tasić G, Djurović B, et al. Hydrocephalic risk factors after spontaneous subarachnoidal haemorrhaging of aneurysmal aetiology. Srp Arh Celok Lek. 2005;133(9-10):401-5.

25. Hirashima $\mathrm{Y}$, Hamada $\mathrm{H}$, Hayashi $\mathrm{N}$, et al. Independent predictors of late hydrocephalus in patients with aneurysmal subarachnoid hemorrhage-analysis by multivariate logistic regression model. Cerebrovasc Dis. 2003;16:205-10.

26. Kanat A, Turkmenoglu O, Aydin MD, et al. Toward changing of the pathophysiologic basis of acute hydrocephalus after subarachnoid hemorrhage: a preliminary experimental study. World Neurosurg. 2013;80:390-5.

27. Hoh BL, Kleinhenz DT, Chi YY, et al. Incidence of ventricular shunt placement for hydrocephalus with clipping versus coiling for ruptured and unruptured 
cerebral aneurysms in the Nationwide inpatient sample database: 2002 to 2007. World Neurosurg. 2011;76:548-54.

28. Goergen SK, Barrie D, Sacharias N, et al. Perimesencephalic subarachnoid haemorrhage: negative angiography and favourable prognosis. Australas Radiol. 1993;37(2):156-60.

29. Grand W, Chamczuk AJ, Leonardo J, et al. Endoscopic third ventriculostomy for hydrocephalus after perimesencephalic subarachnoid hemorrhage: initial experience in three patients. Acta Neurochir. 2011;153(10):2049-55. discussion 2055-6

30. Sorteberg W, Slettebo H, Eide PK, et al. Surgical treatment of aneurysmal subarachnoid haemorrhage in the presence of 24-h endovascular availability: management and results. Br J Neurosurg. 2008;22:53-62.

Ready to submit your research? Choose BMC and benefit from:

- fast, convenient online submission

- thorough peer review by experienced researchers in your field

- rapid publication on acceptance

- support for research data, including large and complex data types

- gold Open Access which fosters wider collaboration and increased citations

- maximum visibility for your research: over $100 \mathrm{M}$ website views per year 